\title{
A agroindústria familiar no contexto do sistema agrário colonial no Sul do Brasil
}

\author{
Virginia Elisabeta Etges \\ Universidade de Santa Cruz do Sul - Santa Cruz do Sul - RS - Brasil \\ ORCID: https://orcid.org/0000-0002-6976-8363 \\ Erica Karnopp \\ Universidade de Santa Cruz do Sul - Santa Cruz do Sul - RS - Brasil \\ ORCID: https://orcid.org/0000-0001-5976-2331
}

\section{Resumo}

A configuração do território rural no sul do Brasil foi fortemente influenciada pela imigração europeia ao longo do século XIX. O sistema agrário colonial, decorrente desse processo, é caracterizado pela pequena propriedade rural, organizada em regime de trabalho familiar, voltada à produção da subsistência do grupo familiar e à venda de excedentes. Os dados apresentados resultam da pesquisa que analisou o processo de constituição e de funcionamento das agroindústrias familiares e suas implicações na dinâmica da organização territorial na região do Vale do Rio Pardo - RS. Por meio da investigação, de caráter analíticoexplicativo, buscou-se compreender a interação de fatores de ordem endógena (horizontalidades) e de ordem exógena (verticalidades) no território, uma vez que a região é hegemonizada por grandes complexos transnacionais da indústria do tabaco, que usam o território de forma seletiva, tornando os produtores dependentes de suas estratégias de produção e de comercialização. Os dados coletados apontam dificuldades na formalização das agroindústrias, em decorrência das exigências legais. Do total de agroindústrias identificadas na região, em torno de $40 \%$ são formais e $60 \%$ estão em processo de formalização ou são informais, condição que limita o acesso ao mercado formal para comercialização da produção.

Palavras-chave: Território. Sistema agrário colonial. Agroindústria familiar. Cultivo do tabaco. Dependência. Autonomia.

\section{The family agroindustries in the context of the colonial agrarian system in Southern Brazil}

\section{Abstract}

The configuration of rural territory in southern Brazil has been strongly influenced by European immigration throughout the 19th century. The colonial agricultural system, resulting from this process, is characterized by the small rural property, organized around family work, focused on the production for subsistence and commercialization of surplus production. The data here presented is a result of a research that analyzes the constitution process and functioning of family agroindustries and its implications on the dynamic of territorial organization in the Vale do Rio Pardo - RS region. Through this investigation, one of analytical-explicative nature, we sought to understand the interaction of endogenous (horizontalities) and exogenous (verticalities) factors in territory, since the region is 
hegemonized by the large transnational complexes of the tobacco industry, which use the territory in a selective way, making producers dependent on their production and marketing strategies The data collected show difficulties in the formalization of agroindustries because of legal requirements. From all agroindustries units identified in the region, approximately $40 \%$ are formal and $60 \%$ are in the process of formalization or are informal, a condition that limits the access to the formal market to commercialize the production.

Keywords: Territory. Colonial agrarian system. Family agroindustries. Tobacco growing. Dependency. Autonomy.

\section{Agroindustria familiar en el contexto del sistema agrario colonial en el Sur de Brasil}

\section{Resumen}

La configuración del territorio rural en el sur de Brasil estuvo fuertemente influenciada por la inmigración europea durante el siglo XIX. El sistema agrario colonial, resultante de este proceso, se caracteriza por pequeñas propiedades rurales, organizadas bajo el trabajo familiar, destinadas a la producción de subsistencia del grupo familiar y la venta de excedentes. Los datos presentados son el resultado de una investigación que analizó el proceso de constitución y operación de agroindustrias familiares y sus implicaciones en la dinámica de la organización territorial en la región de Vale do Rio Pardo - RS. A través de la investigación analítica explicativa, buscamos comprender la interacción de factores endógenos (horizontalidades) y factores exógenos (verticalidades) en el territorio, ya que la región está hegemonizada por grandes complejos transnacionales de la industria tabacalera, que utilizan el territorio de forma selectiva, lo que hace que los productores dependan de sus estrategias de producción y comercialización. Los datos recopilados indican dificultades para formalizar las agroindustrias, debido a requisitos legales. Del total de las agroindustrias identificadas en la región, alrededor del $40 \%$ son formales y el $60 \%$ están en proceso de formalización o son informales, una condición que limita el acceso al mercado formal para la comercialización de la producción.

Palabras llave: Territorio. Sistema agrario colonial. Agroindustria familiar. Cultivo de tabaco. Dependência. Autonomia.

\section{Introdução}

A análise da dimensão territorial dos processos de desenvolvimento vem sendo reconhecida por pesquisadores de diversas áreas do conhecimento. Da mera aplicação de modelos matemáticos generalizantes avança-se para a compreensão do significado dos arranjos territoriais particulares, que configuram a diversidade presente no território. A dimensão da particularidade se manifesta no território por meio da região, a qual se origina de Formações Sócio Espaciais (SANTOS, 1982) que expressam características políticas, econômicas, sociais, culturais e ambientais também particulares, configuradas ao longo do tempo, nas diversas porções da superfície terrestre.

O sistema agrário colonial presente na região do Vale do Rio Pardo, no Estado do Rio Grande do Sul, resulta do processo de colonização da região por imigrantes europeus no século XIX. Trabalhando em regime de produção familiar, produziam os bens necessários para a sua subsistência e vendiam os excedentes.

Instalados em pequenos lotes de terra em áreas de Mata Subtropical Atlântica enfrentaram adversidades de várias ordens, como a falta de instrumentos de 
trabalho, a dificuldade em obter sementes, a luta contra animais selvagens que destruíam as lavouras e, acima de tudo, a luta contra a fome e a miséria.

Nesse contexto, produzir alimentos e desenvolver formas de conservá-los tornou-se uma estratégia de garantia da sobrevivência das famílias. Portanto, a origem das agroindústrias familiares, cada vez mais presentes na região na atualidade, está diretamente relacionada à necessidade de conservar alimentos, verificada desde o período da colonização da região.

Os dados apresentados resultam de uma pesquisa realizada nos municípios da região do Vale do Rio Pardo/RS, no período de 2015 a 2018, com apoio financeiro do CNPq, com o objetivo de analisar o processo de constituição e de funcionamento das agroindústrias familiares e suas implicações na dinâmica da organização territorial na região. Por meio de reuniões com agricultores familiares proprietários de agroindústrias e de entrevistas semiestruturadas, foram coletados dados sobre as estratégias de atuação e organização, bem como as principais tendências e desafios das agroindústrias, e sua repercussão no território. Foram realizadas 40 entrevistas com proprietários de agroindústrias familiares, identificados com o auxílio de informantes qualificados vinculados à Emater, a Secretarias municipais de Agricultura, aos Sindicatos de Trabalhadores Rurais e ao Arranjo Produtivo Local de Agroindústria e Alimentos do Vale do Rio Pardo.

Este artigo está organizado em quatro itens. O primeiro trata da formação sócio espacial e o sistema agrário colonial no Sul do Brasil; o segundo item aborda o território e o desenvolvimento de agroindústrias familiares, seguido do terceiro, que discute a agroindústria familiar na região do Vale do Rio Pardo. O quarto item aborda a agroindústria familiar no contexto do sistema agrário colonial no Sul do Brasil, culminando com as considerações finais.

\section{Formação sócio espacial e o sistema agrário colonial no sul do Brasil}

O conceito de Formação Sócio Espacial, proposto por Milton Santos, tornouse crucial para a análise geográfica e, do mesmo modo, para o entendimento dos processos de diferenciação espacial, especialmente em escalas particulares. (CORRÊA, 1995).

Santos (1982, p.10) afirma que

a categoria Formação Econômica e Social parece-nos a mais adequada para auxiliar a formação de uma teoria válida do espaço. Esta categoria diz respeito à evolução diferencial das sociedades, no seu quadro próprio e em relação com as forças externas de onde mais frequentemente lhes provém o impulso. A base mesma da explicação é a produção, isto é, o trabalho do homem para transformar, segundo leis historicamente determinadas, o espaço com o qual o grupo se confronta. Deveríamos até perguntar se é possível falar de Formação Econômica e Social sem incluir a categoria do espaço. Trata-se de fato de uma categoria de Formação Econômica, Social e Espacial mais do que de uma simples Formação Econômica e Social (FES), tal qual foi interpretada até hoje.

De acordo com Correa (1997), a diferenciação de áreas, resultante tanto de processos da natureza como de processos sociais, constitui-se na base da possibilidade de se poder falar em região. Mas a diferenciação de áreas não está 
associada à ideia de singularidade, que entendemos vincular-se ao conceito de lugar, mas sim à ideia de particularidade, isto é, uma mediação entre o universal (processos gerais advindos da globalização) e o singular (a especificação máxima do universal). Citando Lukács (1967), afirma que a particularidade, com relação ao singular, representa uma universalidade relativa e, com relação ao universal, uma singularidade relativa. A particularidade traduz-se, portanto, no plano espacial, na região.

"Os modos de produção escrevem a história no tempo, as formações sociais escrevem-na no espaço", afirma Santos (1982, p.15). Ambas, lógicas universais e singulares, passam a refletir combinações particulares que, ao se concretizarem, o fazem de modo distinto, criando e sustentando as diversidades. De fato, a formação social é uma particularidade espaço-temporal de um determinado modo de produção, quer dizer, é uma combinação particular e relacional de uma ordem temporal e de uma ordem espacial de um dado modo de produção dominante. (BESSA, 2010).

Segundo Santos (1982), em tempos de globalização, com um modo de produção que tende a ser único, o espaço geográfico seria homogeneizado ou uniformizado por intermédio da ação de uma unicidade técnica, que se orienta no plano do universal. Todavia isso não ocorre, pois a ação deste modo de produção, tendencialmente único, passa pela mediação das formações sócio espaciais, situada no plano da particularidade.

O sistema agrário colonial do sul do país é expressão desse arranjo territorial particular, expresso no modo de vida e nas formas de organização e produção dos agricultores familiares.

Sistema Agrário é um modo específico de artificialização da natureza, visando a obtenção de produtos biológicos de interesse do homem. Assim, ao contrário de considerar as regiões onde a agricultura é praticada através de técnicas que não usam insumos e equipamentos de origem industrial como um bloco homogêneo (denominado genericamente de "agricultura tradicional" pela Teoria da Modernização), uma análise em termos de sistemas agrários procura definir, para cada região considerada, os fatores históricos e geográficos responsáveis pela dinâmica de acumulação dos meios de produção e de diferenciação social dos agricultores, cuja coerência forma um "sistema agrário". (SILVA NETO; LIMA; BASSO, 1997, p. 12).

Trata-se, portanto, de temporalidades diversas coexistindo num mesmo território que imprimem características particulares ao que denominamos região.

Cada sistema agrário é a expressão teórica de um tipo de agricultura historicamente constituído e geograficamente localizado. Ele é composto de um ecossistema cultivado característico e de um sistema social produtivo definido, que permite explorar sustentavelmente a fertilidade do ecossistema cultivado correspondente. O sistema produtivo é caracterizado pelo tipo de instrumento e de energia utilizado para transformar o ecossistema, para renovar e para explorar sua fertilidade. O tipo de instrumento e de energia utilizado é, por sua vez, condicionado pela divisão do trabalho que predomina na sociedade da época. (MAZOYER; ROUDART, 2010, p. 75)

Fundamental nesse processo de difusão de novas técnicas aos imigrantes foi a própria organização social do espaço ensejada pela imigração. Os colonizadores 
europeus foram instalados em pequenos povoados - vilas ou picadas -, que não passavam, inicialmente, de aglomerados rurais, nos quais se constituíam os centros administrativos das colônias e também seu centro comercial, artesanal, escolar, religioso e social.

Essa organização social foi muito importante na reprodução do sistema agrário colonial, porque essas vilas funcionavam como ponto de encontro dos agricultores. Era onde se trocavam, além das mercadorias, as experiências agrícolas de como produzir, quais as técnicas mais apropriadas para o cultivo de cada produto e o que produzir. Ali se realizavam as reuniões sociais, as festas, os encontros entre os jovens e os casamentos. Era para esses aglomerados que se dirigiam os novos imigrantes, de passagem para suas colônias. Esses pequenos povoados serviam também como elo entre o colono e os centros urbanos maiores, através dos comerciantes locais, que compravam seus produtos e lhes vendiam outros e que, muitas vezes, recomendavam aos colonos o que produzir, qual era o produto mais solicitado nos mercados maiores. (MERTZ, 2004)

Entende-se, portanto, que um sistema agrário "é a representação teórica de um tipo de agricultura historicamente constituído e geograficamente localizado" (MERTZ, 2004, p. 279), cujas características, no caso da região colonial do sul do Brasil, remontam ao século XIX e continuam presentes até os dias atuais.

\section{0 território e o desenvolvimento de agroindústrias familiares}

A configuração do mundo rural no sul do Brasil foi fortemente influenciada pela imigração europeia ao longo do século XIX. Em suas regiões de origem (Europa Central, atual Alemanha e Polônia, Península Itálica, entre outras) essas populações vinham enfrentando a fome e a miséria, decorrentes da desestruturação do Modo de Produção Feudal (que se deu tardiamente nessas regiões, quando comparadas à Inglaterra ou à França), e da estruturação de formas de produção capitalistas, expressas na intensificação do uso da terra, o que condicionava inúmeras famílias de camponeses à migração, em busca de sobrevivência.

Nesse contexto surge a possibilidade de migrar para o Novo Mundo, a América. Havia, entretanto, uma motivação central que colocou essas populações em movimento e que as levou a emigrar, que era a possibilidade do acesso à propriedade da terra. Para compreender e avaliar a dimensão dessa promessa é preciso compreender que se tratava de populações que traziam a herança de terem vivido durante séculos na condição de servos, no contexto do feudalismo e, posteriormente, na condição de camponeses, condições essas que os privavam da possibilidade do acesso à propriedade da terra.

A propaganda da emigração, realizada pelos agentes especialmente enviados à Europa para essa finalidade, tinha na questão da promessa do acesso à propriedade da terra o seu principal argumento: "Se a promessa de se tornarem proprietários se colocava como o mais intenso motivador da aventura emigratória, a terra vai constituir-se no bem maior do colono" (TRAMONTINI, 1994, p.55).

Uma vez instalados nas "suas" terras no sul do país, os colonos embrenhavamse na mata para abrir as primeiras clareiras, construir abrigos e lançar sementes à terra para produzir alimentos. 
Com famílias numerosas, era necessário produzir mais e mais alimentos para prover a subsistência dos filhos, muitas vezes em número superior a uma dezena. À medida que se ambientavam na "nova vida" e a produção aumentava, passaram a diversificar a produção e a produzir excedentes, a serem vendidos em algum mercado próximo. Mas havia uma preocupação central: era preciso guardar alimentos para eventuais períodos de intempéries ou de escassez e para isso era preciso desenvolver técnicas de conservação. É nesse contexto que surgiu, por exemplo, a forma mais difundida nas colônias de conservação da carne de porco. A carne era frita em tachos de ferro e depois colocada em vasilhames, imersa na própria banha resultante do processo de fritura e ali era conservada por meses.

Outras formas de conservar alimentos, principalmente entre os imigrantes alemães, era o chucrute (Sauerkraut), elaborado com repolho picado, que era prensado em vasilhames em camadas alternadas com sal. Depois de passar por um processo de fermentação, era consumido cru ou cozido no vapor.

Além desses, havia também a preocupação em conservar frutas, cuja sazonalidade limitava o seu aproveitamento in natura. Para tanto, utilizavam técnicas de desidratação, para depois expô-las ao sol para secarem. Assim, as frutas poderiam ser utilizadas em outras épocas do ano para preparação de sobremesas ou de cucas.

Isso faz com que, na atualidade, para os agricultores familiares, a industrialização de produtos agropecuários não seja novidade, pois faz parte de sua história, cultura e identidade. (TRENTIN, 2002).

No contexto histórico, os imigrantes trouxeram de suas origens europeias, a bagagem cultural, as práticas da ajuda mútua, o trabalho associativo e as atividades familiares, além do gosto pelo trabalho comunitário. Partindo desses princípios, fortaleceram as práticas da cooperação, difundidas no sul do Brasil a partir do século XIX.

Assim, a partir de meados da década de 1990, há um aumento significativo na oferta de produtos agroindustrializados, sobretudo nas feiras livres e em vendas diretas aos consumidores, de produtos advindos de cooperativas e associações ligadas aos agricultores familiares. Através desse processo observa-se uma crescente agregação de valor à produção primária, viabilizando o aumento da renda nas unidades familiares, bem como o incremento à diversificação da produção e ao resgate do "saber fazer", ainda presente entre várias famílias da região sul do Brasil.

Essas constatações nos levam a repensar o conceito de território, não mais entendido como "palco" ou mero receptáculo, e sim como território usado. Ou seja, a definição e a análise de um dado território devem "levar em conta a interdependência e a inseparabilidade entre a materialidade, que inclui a natureza, e o seu uso, que inclui a ação humana, isto é, o trabalho e a política". (SANTOS e SILVEIRA, 2001, p. 247). Essa ideia de território usado expressa a noção de mudança, de processo, de movimento, uma vez que "[...] é o território que constitui o traço de união entre o passado e o futuro imediatos. Ele tem de ser visto [...] como um campo de forças, como o lugar do exercício, de dialéticas e contradições entre o vertical e o horizontal, entre o Estado e o mercado, entre o uso econômico e o uso social dos recursos." (SANTOS, 1999, p.19).

Nas atuais condições, os arranjos espaciais não se dão apenas através de figuras formadas de pontos contínuos e contíguos. Hoje, ao lado dessas manchas, ou por sobre essas manchas, há, também, constelações de 
pontos descontínuos, mas interligados, que definem um espaço de fluxos reguladores. As segmentações e partições presentes no espaço sugerem, pelo menos, que se admitam dois recortes. De um lado, há extensões formadas de pontos que se agregam sem descontinuidade, como na definição tradicional de região. São as horizontalidades. De outro lado, há pontos no espaço que, separados uns dos outros, asseguram o funcionamento global da sociedade e da economia. São as verticalidades. O espaço se compõe de uns e de outros desses recortes, inseparavelmente. É a partir dessas novas subdivisões que devemos pensar novas categorias analíticas. (SANTOS, 2006, p.225).

No caso particular da região do Vale do Rio Pardo a manifestação da força da verticalidade se expressa por meio da ação das empresas transnacionais do tabaco, que exercem na região um comando, que atua em rede e atende a interesses exógenos, globais, tendo o mercado como única referência. A horizontalidade manifesta-se por meio da resistência e da organização dos atores regionais, que buscam fortalecer-se por meio de associações e cooperativas, fortalecendo laços de pertencimento, tendo como referência o território, entendido como espaço de vida.

É nesse contexto que o associativismo adquire novo sentido na região, pois permite apreender a lógica e a dinâmica pelas quais os agentes sociais envolvidos se relacionam e usam o território. Essas relações dinâmicas entre os agentes e segmentos que atuam no território, se desenvolvem através de distintos tempos sociais e desde diferentes escalas espaciais, configurando arranjos particulares no território, resultantes do embate entre as forças globais e as forças regionais.

Constata-se, assim, que a dinâmica impressa nos arranjos territoriais resulta da interação concomitante de fatores de ordem endógena e exógena.

Nesse contexto é fundamental que as teorias e ações voltadas ao desenvolvimento regional produzam também reflexões teoricamente fundamentadas e apoiadas em experiências concretas, e demonstrem que têm capacidade de gerar contrapontos viáveis à globalização, sobretudo em termos de implicações para a vida rural, para a viabilidade da agricultura familiar e para a qualidade ambiental.

\section{A agroindústria familiar na Região do Vale do Rio Pardo}

A região do Vale do Rio Pardo/RS tem sua base econômica assentada na produção do tabaco, realizada por agricultores familiares em pequenas unidades de produção, e no beneficiamento desse produto, operado por empresas transnacionais do setor, instaladas na região.

A produção, o beneficiamento e a exportação do tabaco colocam a região como lócus privilegiado para a análise das dinâmicas socioeconômicas no território, expressas na ação das forças globais que monopolizam o território, colocando-o a seu serviço.

A busca por alternativas à cultura do tabaco pelos agricultores familiares é evidenciada pelo número crescente de agroindústrias familiares que vêm sendo constituídas na região. Porém, por serem, na sua maioria, agroindústrias de pequeno porte, elas enfrentam grandes dificuldades de organização e de gestão, o que compromete a sua sustentabilidade. 
O Vale do Rio Pardo está localizado na porção centro-oriental do Estado do Rio Grande do Sul, como mostra a Figura 1.

Figura 1 - Região do Vale do Rio Pardo

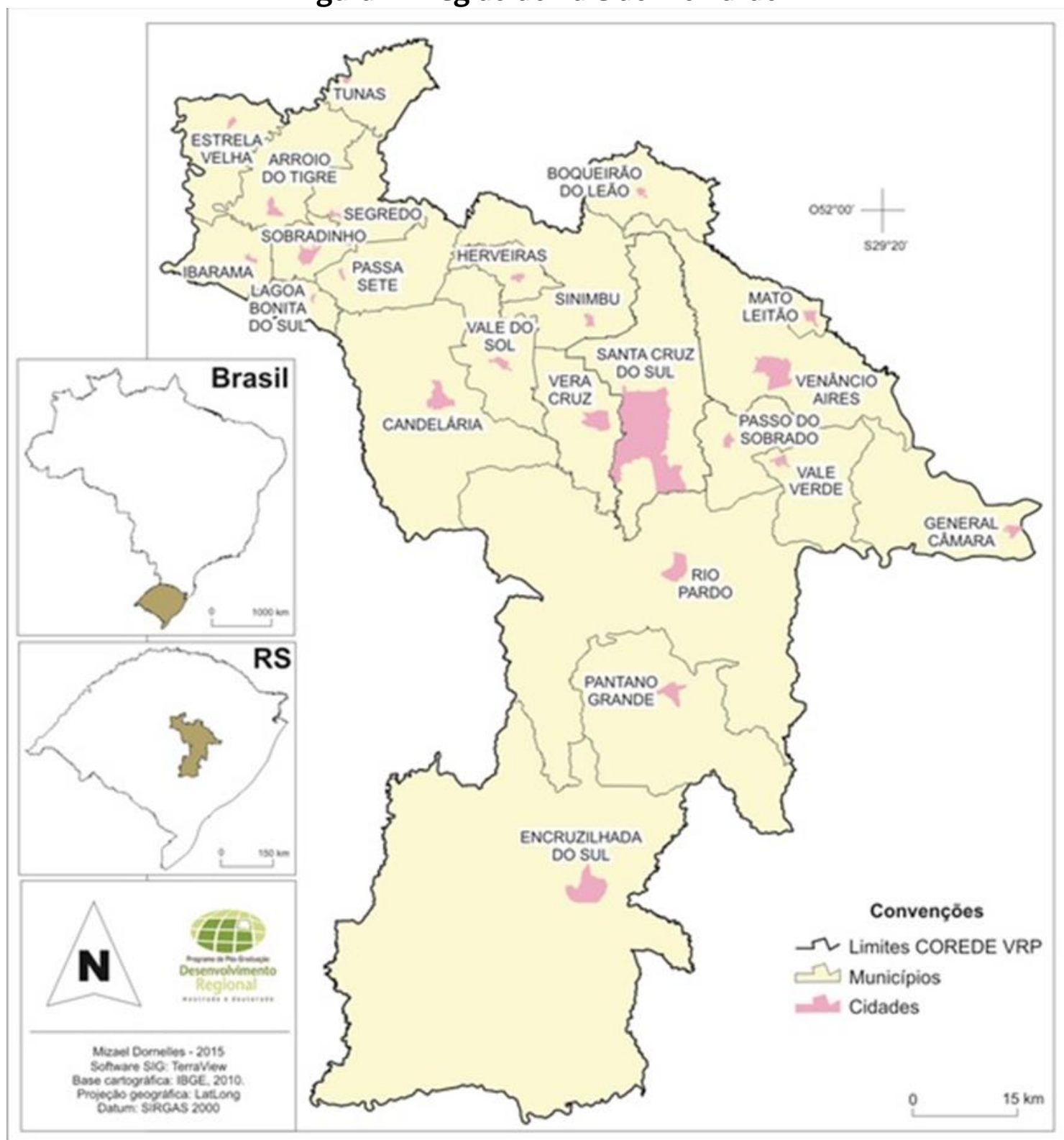

Fonte: IBGE, 2010, elaborado por Dornelles, 2015.

Durante o século XIX, várias regiões do RS foram colonizadas por imigrantes de origem europeia. No Vale do Rio Pardo a partir de meados do século XIX, colonos alemães foram assentados em duas colônias instaladas e geridas pela Província. No então território do município de Rio Pardo surgiu, em 1849, a Colônia Santa Cruz, que Colônia Santa Cruz progrediu rapidamente, apesar das dificuldades que enfrentou com a falta de estradas para o escoamento da produção. O tabaco desde cedo se tornou o principal produto da economia não somente de Santa Cruz, mas de todas as colônias da circunvizinhança. (VOGT, 2006).

Ao longo do tempo, a cultura do tabaco permitiu um acúmulo de capital, especialmente a partir do desenvolvimento de suas possibilidades de exportação, dando origem às atividades de beneficiamento e de industrialização deste produto 
nos municípios de Santa Cruz do Sul e Venâncio Aires. Entretanto, este capital foi sendo concentrado pelas grandes indústrias transnacionais, que hoje controlam de forma oligopsônica todo o mercado do setor. Decisivamente as corporações transnacionais têm um grande impacto no território.

O modelo de desenvolvimento econômico construído no país a partir da década de 1950, através da implementação da Revolução Verde e do correspondente pacote tecnológico, foi pautado em uma política homogeneizadora que, por muitos anos, ocultou a capacidade de organização dos agricultores, retirando-lhes poder de decisão e colocando-os como meros receptores de tecnologias e políticas. Embora este processo tenha efetivamente aumentado a produtividade agrícola, trouxe como um dos desdobramentos sociais mais evidentes a redução da capacidade dos agricultores de organizarem e administrarem sua produção, provocando ainda mais a marginalização de suas iniciativas. (BUAINAIN; ROMEIRO; GUANZIROLI, 2003)

Desta forma, é necessário salientar que a Revolução Verde não foi pacificamente absorvida pelos agricultores. Processos de resistência e construção de alternativas foram surgindo em diferentes temporalidades, com repercussões diversas. Em todos, no entanto, o que se observa, é a menor ou maior capacidade das lideranças e dos agricultores em analisar a realidade e construir respostas adequadas ao modelo de desenvolvimento vigente. (PLOEG, 2006).

Um desses processos de resistência e busca de alternativas está no número crescente de agroindústrias familiares, que vêm sendo constituídas em todas as regiões do Brasil. Porém, por serem, na sua maioria, agroindústrias familiares, de pequeno porte, elas enfrentam enormes dificuldades de organização e de gestão, o que compromete a sua sustentabilidade.

Entretanto, considera-se que as dificuldades e os limites existentes na organização dos agricultores, como os aspectos legais e organizacionais das agroindústrias, devem ser relativizados e vinculados às questões políticas e históricas desse setor, bem como, com sua capacidade de articulação regional e nacional na construção de redes eficazes de apoio mútuo. Compreendê-las no contexto do sistema agrário colonial em que estão inseridas, destacando suas características e tendências mais recentes, torna-se indispensável a fim de contribuir para a formulação de políticas públicas de desenvolvimento para a agricultura familiar.

Existem, atualmente, cerca de 160 agroindústrias familiares na região, segundo informações da EMATER (2014). Destes empreendimentos, em torno de 40\% são formais e $60 \%$ em processo de formalização ou informais. A informalidade limita o acesso ao mercado formal. O fator da informalidade também contribui para que os empreendedores produzam abaixo de sua capacidade. Como exemplos, podem ser citadas as agroindústrias familiares de produtos cárneos e panifícios, de derivados da cana de açúcar, frutas e vitivinicultura, entre outras.

As iniciativas de formação e legalização de agroindústrias familiares surgiram na região com mais força na década de 1990, a partir de incentivos governamentais. No entanto, a exigência em termos legais para a formalização desestimulou grande parte das iniciativas, tendo em vista que as regras estabelecidas na legislação federal e estadual eram voltadas à realidade das agroindústrias de grande porte. Contudo, este cenário modificou-se a partir da Lei 13.840 de 2011, que instituiu a Política Estadual de Agroindústria Familiar. 


\section{A agroindústria familiar no contexto do sistema agrário colonial no sul do Brasil}

De acordo com Prezotto (2002), a agroindústria rural de pequeno porte não proporciona os ganhos da economia de grande escala. Isto porque ela é constituída em uma outra lógica, de um jeito próprio, diferente da agroindústria convencional, que tem na grande escala o eixo principal para a sua viabilidade econômica.

Trata-se de uma importante alternativa de geração de renda no meio rural em que processar e comercializar a própria produção torna as famílias independentes dos complexos agroindustriais. Os agricultores tornam-se os protagonistas do processo, passando a atuar em toda a cadeia produtiva, além de promovem a descentralização e a diversificação da produção e desenvolvimento local, fortalecendo os valores culturais, a sustentabilidade ambiental e a oferta de produtos diversificados e de qualidade à população.

Foi nesta perspectiva que o Estado do Rio Grande do Sul passou a desenvolver uma série de medidas para fomentar a implantação e a legalização de agroindústrias familiares. Com a criação do Programa Estadual de Agroindústria Familiar (PEAF), por meio do Decreto Estadual $n^{\circ}$ 49.341de 05 de julho 2012, os agricultores familiares interessados em instalar uma agroindústria passaram a contar com uma série de benefícios, tais como: acesso a linhas de crédito com condições facilitadas; ampliação da participação dos agricultores familiares no Programa de Aquisição de Alimentos (PAA) e no Programa Nacional de Alimentação Escolar (PNAE); orientação para regularização sanitária, tributária e ambiental; auxílio na elaboração de projetos para construção, reforma ou ampliação de agroindústrias familiares e cálculo nutricional de receitas através do Escritório Central da Emater; elaboração de layout de rótulos e adequação com a legislação vigente, serviços que passaram a ser executados pela SDR em parceria com a Emater. Adicionalmente, cursos de qualificação nas áreas de gestão, boas práticas de fabricação e processamento dos alimentos são disponibilizados aos beneficiários do Programa. (PEAF, 2013)

Por meio dessa política pública, as agroindústrias familiares e os Serviços de Inspeção Municipais (SIM) passaram a receber orientações quanto à implantação e adequação, bem como o acesso destes empreendimentos e dos municípios ao Sistema Unificado Estadual de Sanidade Agroindustrial Familiar, Artesanal e de Pequeno Porte (SUSAF-RS) e ao Sistema Brasileiro de Inspeção de Produtos de Origem Animal (SISBI/POA), pertencente ao Sistema Unificado de Sanidade Agropecuária (SUASA). (PEAF, 2013)

A essa política estadual soma-se ainda o Programa de Aquisição de Alimentos (PAA), criado pela Lei Federal n 10.696 de 02 de julho de 2003, e o Programa Nacional de Alimentação Escolar (PNAE), regulamentado pela Lei Federal nº 11.947 de 16 de junho de 2009, como políticas públicas que incentivam a agricultura familiar, viabilizando importantes espaços de comercialização da produção, tanto produtos in natura quanto os processados nas agroindústrias.

Na região do Vale do Rio Pardo, apesar das agroindústrias familiares terem surgido há mais de 25 anos, é somente a partir dos anos 2000, por meio das políticas públicas voltadas ao segmento, que elas se fortalecem e crescem em número. São iniciativas que se estruturaram no contexto familiar, na passagem de conhecimentos de geração para geração e com a utilização prioritária de mão de obra familiar envolvendo, muito raramente, mão de obra de terceiros. 
Os dados aqui apresentados foram coletados por meio de 40 entrevistas com proprietários de agroindústrias familiares, identificados com o auxílio de informantes qualificados vinculados à Emater, a Secretarias Municipais de Agricultura, aos Sindicatos de Trabalhadores Rurais e ao Arranjo Produtivo Local de Agroindústria e Alimentos do Vale do Rio Pardo.

Dentre as agroindústrias pesquisadas, a maioria é formalizada, sendo que $80 \%$ estão nesta condição desde 1986. Já as agroindústrias informais são menos visíveis, dificultando, inclusive, o contato para levantamento de dados.

As atividades de processamento dos produtos agroindustriais são, em geral, realizadas pelas mulheres, uma vez que são elas que trazem consigo as heranças do "saber fazer". Os dados coletados, entretanto, revelam que dos respondentes dos questionários, $60 \%$ são do gênero masculino, evidenciando o papel do homem na função de gestor do empreendimento. De acordo com Mior (2005), é na esfera da produção da agroindústria que as mulheres se destacam, pois a tradição da produção artesanal por parte da mulher agricultora marca em muitos casos o ponto inicial para a ampliação da atividade em termos de escala e rearranjo produtivo da propriedade rural.

Quanto à escolaridade, os respondentes cursaram predominantemente até o ensino médio. Esta condição é aceitável, mas pode não ser suficiente para assegurar a continuidade dos empreendimentos, sobretudo nos aspectos relacionados à modernização tecnológica. Amorim e Staduto (2007) advertem que a maior escolaridade potencializa a conversão do capital humano em capacidade de gerenciamento, inovação de processos e novas técnicas produtivas.

Quanto à origem da matéria prima empregada nos processos produtivos das agroindústrias, pelo menos $50 \%$ é adquirida de terceiros. Na região do VRP 23,3\% das agroindústrias pesquisadas atendem suas demandas com produtos da própria unidade familiar. Com relação à cooperação observou-se que apenas 10\% dos respondentes são cooperativados, evidenciando uma tendência à individualização dos empreendimentos, que é uma característica do sistema "integrado" de produção do tabaco, fortemente disseminada na região. Os entrevistados entendem as agroindústrias como uma alternativa à produção do tabaco e uma possibilidade de aumento da renda familiar. Constata-se, assim, que a dinâmica impressa nos arranjos territoriais resulta da interação concomitante de fatores de ordem endógena e exógena.

Essa perspectiva também se evidencia na rivalidade entre os proprietários das agroindústrias, em que 70,1\% dos entrevistados veem as demais como concorrentes, contra $28,4 \%$ que as veem como parceiras.

Quanto à motivação para a constituição da agroindústria, o aumento da renda foi. apontado por $81,1 \%$ dos respondentes. A atividade das agroindústrias na geração da renda das famílias é superior a $50 \%$ da renda bruta para $70,3 \%$ dos entrevistados da região.

Quanto ao capital inicial para a constituição da agroindústria, as fontes de recursos eram de $73 \%$ de capital próprio, sendo a diferença coberta com recursos de alguma forma de financiamento. Aproximadamente um terço dos empreendimentos pesquisados reconhece o apoio dos incentivos municipais para a instalação de seus empreendimentos. 
As agroindústrias familiares pesquisadas destinam 95\% de sua produção ao mercado, sendo que a abrangência local é de aproximadamente $60 \%$ e a abrangência regional é de aproximadamente 38\%. Mais de $80 \%$ dos entrevistados afirmam que os preços de seus produtos são menores ou iguais aos preços dos produtos similares das agroindústrias convencionais.

No tocante às ações para inserção no mercado, entre as agroindústrias pesquisadas $70 \%$ utilizam rótulos em seus produtos, sendo que $67 \%$ atendem às exigências de regularidade de fornecimento aos clientes. No entanto, na maioria dos casos não existe preocupação com a apresentação do produto e com planos de marketing. A padronização da produção é um problema identificado nas agroindústrias pesquisadas.

Em relação às condições de desempenho geral, a região do VRP apresenta baixo dinamismo, pois $51 \%$ das agroindústrias pesquisadas não aumentaram 0 processo produtivo, e nenhuma agroindústria pesquisada dobrou de tamanho. Para os próximos anos, $48 \%$ dos entrevistados têm perspectivas de aumento da produção e comercialização, e 27\% não têm perspectivas de aumentos nesse aspecto.

As agroindústrias estudadas têm a mão de obra como principal fator de restrição ao aumento e à diversificação da produção. A mão de obra é apontada também como a principal dificuldade e fator de restrição para a comercialização, com $55 \%$, seguida pela concorrência e pela legislação, com 35\% e 29\%, respectivamente.

Como alternativa ao desenvolvimento regional, inclusive para as características socioeconômicas e fundiárias no sul do país, o desenvolvimento da agroindústria familiar tem importantes desdobramentos no território, com a possibilidade de melhorias das condições de renda e da qualidade de vida. Tendo em vista os processos de reestruturação capitalista e o aumento da vulnerabilidade social e econômica observados na região estudada, diversas iniciativas têm se voltado ao incremento da diversificação produtiva no âmbito da agricultura familiar.

Nesse contexto é fundamental que as ações voltadas ao desenvolvimento regional produzam também reflexões teoricamente fundamentadas e apoiadas em experiências concretas, e demonstrem que têm capacidade de gerar contrapontos viáveis à globalização, sobretudo em termos de implicações para a vida rural, para a viabilidade da agricultura familiar e para a qualidade ambiental nos distintos territórios.

\section{Considerações Finais}

$\mathrm{Na}$ região objeto deste estudo, várias estratégias de desenvolvimento, determinadas por dinâmicas econômicas endógenas, têm sido identificadas.

Com as políticas públicas voltadas à agricultura familiar, implementadas, tanto em nível federal quanto estadual, desde o início dos anos 2000 até o ano de 2016, observou-se uma crescente dinamização e fortalecimento de iniciativas voltadas ao desenvolvimento rural na região do Vale do Rio Pardo. Dentre elas destacaram-se o Programa de Aquisição de Alimentos (PAA), o Programa Nacional de Alimentação Escolar (PNAE), o Programa Estadual de Agroindústria Familiar (PEAF) e o Arranjo Produtivo Local de Agroindústria e Alimentos do Vale do Rio Pardo (APLVRP). A implementação dessas políticas possibilitou a ampliação do mercado para os produtos da agricultura familiar, dentre eles os produtos das agroindústrias. 
Ao mesmo tempo, constata-se que transformações em curso na região estudada evidenciam processos de desvitalização de expressivos espaços rurais, determinados pelo envelhecimento da população, pela mobilidade regional, retração urbana de pequenas cidades e pela concentração populacional em determinados centros urbanos de maior porte.

Nesse contexto, a constituição de agroindústrias familiares pode ser vista como um processo de reconfiguração de espaços rurais. De um produto destinado à subsistência da família rural, o produto colonial processado passa a ser visto pelos agricultores como um produto comercial, com um valor de troca e, portanto, como fonte de renda da unidade de produção familiar. Este processo promove a inserção dos agricultores familiares nos mercados, contribuindo com a estabilidade de renda e a melhoria das condições de vida nas propriedades rurais.

Entretanto, a incorporação da qualidade ampla nos produtos e no processo produtivo, não é suficiente, como aponta Prezotto (2002). É necessária a promoção de uma estratégia de "diálogo educativo" da agroindústria com os consumidores sobre os seus produtos. Este processo de comunicação sobre a qualidade dos produtos pode se dar diretamente entre produtores e consumidores, ou através de um mecanismo de sinalização nas embalagens dos produtos. Um conjunto de sinais facilmente compreensíveis, ou na forma de uma pequena mensagem, poderia ser um canal de informação dos aspectos qualitativos de cada alimento. Esta comunicação teria base em um "conceito referencial" de qualidade, com uma categorização dos produtos. Isto poderia representar o início de um processo de consolidação de uma nova visão de qualidade dos alimentos, associada à saúde e à qualidade de vida. Dessa forma a qualidade poderia também representar uma contribuição para um processo de revisão dos hábitos de consumo e a ampliação do espaço da agroindústria familiar no mercado.

Ao viabilizar dinâmicas de desenvolvimento local e regional, estas ações valorizam a diversificação dos sistemas produtivos, proporcionando agregação de valor à produção agrícola e, condições favoráveis para a melhoria das condições de vida da população.

Nesse contexto o Sistema Agrário Colonial que, de acordo com a teoria da modernização deveria estar extinto, persiste, evidenciando as contradições que permeiam a Formação Sócio Espacial da região.

Portanto, a continuidade da trajetória da agroindústria familiar dependerá da capacidade das unidades territoriais em responder ao desafio de manter e aprimorar esta forma de organização e, ao mesmo tempo, fortalecer a inserção regional em novas cadeias produtivas.

\section{REFERÊNCIAS}

AMORIM, Luci S. B.; STADUTO, Jefferson A. R. (2007). Desenvolvimento territorial rural: estudo empírico sobre agroindústria familiar rural no Oeste do Paraná. In: $45^{\circ}$ CONGRESSO DA SOCIEDADE BRASILEIRA DE ECONOMIA, ADMINISTRAÇÃO E SOCIOLOGIA (SOBER), Anais... Londrina, 2007.

BESSA, Kelly. Diferenciação espacial como elemento próprio à natureza da Geografia. Mercator, volume 9, número 20, 2010: set./dez. 
BUAINAIN, A.M.; ROMEIRO, A.R.; GUANZIROLI, C. Agricultura Familiar e o Novo Mundo Rural. Sociologias, ano 5, $n^{\circ} 10$, jul/dez 2003, p. 312-347.

CORREA, Roberto L. Trajetórias Geográficas. Rio de Janeiro: Bertrand Brasil, 1997.

CORRÊA, Roberto L. Espaço, um conceito-chave da Geografia. In: CASTRO, Iná E. de; GOMES, Paulo Cesar da C.; CORRÊA, Roberto L. (Org.). Geografia: conceitos e temas. Rio de Janeiro: Bertrand Brasil, 1995.

DREHER, Martin. Igreja e Germanidade: estudo crítico da história da Igreja Evangélica de Confissão Luterana no Brasil. São Leopoldo: Editora Sinodal, 1984.

FORTES, João Borges. Os casais açorianos: presença lusa na formação do Rio Grande do Sul. Porto Alegre: Martins Livreiro, 1978.

KARNOPP, Erica et al. Agroindústrias Familiares no Sul do Brasil: O Território na perspectiva do desenvolvimento. Revista de Desenvolvimento Econômico - RDE Ano XVIII - V. 2 - N. 34 - Agosto de 2016 - Salvador, BA - p. 666 - 684.

LUKACS, Georg. Existencialismo ou Marxismo. Editora Senzala, 1967.

MAZOYER, Marcel; ROUDART, Laurence. História das agriculturas no mundo: do neolítico à crise contemporânea [tradução de Cláudia F. Falluh Balduino Ferreira]. São Paulo: Editora UNESP; Brasília, DF: NEAD, 2010. 568p.

MERTZ, Marli. A agricultura familiar no Rio Grande do Sul - um sistema agrário colonial. Ensaios FEE, Porto Alegre, v. 25, n. 1, p. 277-298, abr. 2004.

MIOR, Luiz Carlos. Agricultores familiares, agroindústrias e redes de desenvolvimento rural. Chapecó/SC: Argos, 2005.

PLOEG, J.D.Van der. O modo de produção camponês revisitado. In: SCHNEIDER, S. (org.) A diversidade da Agricultura Familiar. Porto Alegre: Editora da UFRGS, 2006.

PROGRAMA ESTADUAL DE AGROINDÚSTRIA FAMILIAR - PEAF. Manual Operativo. Secretaria Estadual do Desenvolvimento Rural, Pesca e Cooperativismo, Governo do Estado do Rio Grande do Sul, 2013. Disponível em: http://www.sdr.rs.gov.br/upload/arquivos/201710/02115021-manual-operativoprograma-estadual-de-agroindustria-familiar-peaf-2017-2-2.pdf Acesso em: 12 set 2018.

PREZOTTO, Leomar L. Uma concepção de agroindústria rural de pequeno porte. Revista de Ciências Humanas, Florianópolis, n. 31, p. 133-153, abr. 2002.

ROCHE, Jean. A colonização alemã e o Rio Grande do Sul. Porto Alegre: Globo, 1969. 
SANTOS, Milton. Sociedade e Espaço: a formação social como teoria e como método. In: Espaço e Sociedade - Ensaios. $2^{\text {a }}$ ed., Petrópolis: Vozes, 1982.

SANTOS, Milton. Pensando o Espaço do Homem. $4^{\text {a }}$ ed., São Paulo: Hucitec, 1997.

SANTOS, Milton. O Território e o Saber Local: Algumas Categorias de Análise.

Cadernos IPPUR, Rio de Janeiro, ano XIII, n², 1999.

SILVA NETO, Benedito; LIMA, Arlindo Preste de; BASSO, David. Teoria dos Sistemas Agrários: Uma nova abordagem do desenvolvimento da Agricultura. Revista de Extensão Rural, Santa Maria, n.4, 1997.

TRAMONTINI, Marcos Justo. A questão da terra na fase pioneira da colonização. In: MAUCH, Claudia. Os alemães no Sul do Brasil. Canoas: Ed. Ulbra, 1994.

TRENTIN, Iran C. L. Avaliação e Acompanhamento da Gestão de 20 Agroindústrias Familiares da Região das Missões/RS. São Luiz Gonzaga, 2002.

VOGT, Olgário P. A Colonização Alemã no Rio Grande do Sul e o capital social. 2006. 435f. Tese (Doutorado em Desenvolvimento Regional) - Universidade de Santa Cruz do Sul, Santa Cruz do Sul, 2006.

WAIBEL, Leo. Capítulos de Geografia Tropical e do Brasil. 2. ed. Rio de Janeiro: IBGE, 1979.

WILLEMS, Emilio. A aculturação dos alemães no Brasil: estudo antropológico dos alemães e seus descendentes no Brasil. São Paulo: Companhia Editora Nacional, 1946.

Virginia Elisabeta Etges. Universidade de Santa Cruz do Sul, RS/Brasil - Doutora em Geografia e Docente do Programa de Pós-Graduação em Desenvolvimento Regional.etges@unisc.br

Erica Karnopp. Universidade de Santa Cruz do Sul, RS/Brasil - Doutora em Geografia e Docente do Programa de Pós-Graduação em Desenvolvimento Regional.erica@unisc.br v. 25, n. 1, jan. 2020. ISSN 1982-6745. DOI: https://doi.org/10.17058/redes.v25i1.14255. 


\section{CONTRIBUIÇÃO DE CADA AUTORA}

Fundamentação teórico-conceitual e problematização: Virginia Elisabeta Etges; Pesquisa de dados e análise estatística: Erica Karnopp;

Elaboração de figuras e tabelas: Erica Karnopp e Virginia Elisabeta Etges;

Fotos: não se aplica;

Elaboração e redação do texto: Virginia Elisabeta Etges e Erica Karnopp;

Seleção das referências bibliográficas: Virginia Elisabeta Etges e Erica Karnopp. 